ARTIGO

Recebido em: 01/09/2016

Aceito em: $17 / 05 / 2017$

\title{
Abordagens contemporâneas sobre avaliação em Arquivologia e Ciência da Informação: macroavaliação, avaliação do fluxo informacional e modelo indício-evidência-prova
}

\author{
Contemporary approaches of evaluation of information in Archival Science and \\ Information Science: macro appraisal, analysis of the information flow and \\ clue-evidence-proof model
}

Lisiane Braga FERREIRA (lisianebf@gmail.com)*
Moisés ROCKEMBACH (moises.rockembach@ufrgs.br) ${ }^{* *}$
* Mestranda em Comunicação e Informação - UFRGS.
** Professor do Departamento de Ciências da Informação e Programa de Pós-Graduação em
Comunicação e Informação - UFRGS.

\section{Resumo}

Aborda o tema avaliação da informação em Arquivologia e Ciência da Informação, que sofre influências por um cenário atual em que passamos a conviver com o paradigma pós-custodial. Contextualizamos o surgimento da avaliação enquanto prática arquivística e a transição de para um novo paradigma. Destacamos a emergência de três fenômenos, a partir da consciência de anomalias existentes nas teorias sobre avaliação da informação/documentação: o primeiro relacionado à análise do contexto da produção documental, utilizando para isto de uma abordagem pós-moderna; um segundo fenômeno relacionado à análise do fluxo informacional e uma abordagem da Ciência da Informação inter e transdisciplinar e, por fim um terceiro fenômeno relacionado à análise conceitual da informação como valor de prova, enquanto discurso emancipador da Arquivologia como campo disciplinar e uma abordagem a partir de um Modelo Indício-Evidência-Prova. Pesquisa exploratória com abordagem teórica, predominantemente qualitativa, envolvendo analisar a produção bibliográfica nacional e internacional sobre o tema. Concluímos com a importância da pesquisa na área, destacando a pouca literatura sobre o tema com o viés pós-custodial e possibilidade de suscitar novos questionamentos que podem quebrar o status quo estabelecido na avaliação em Arquivologia, levando a discutir o papel das Instituições e do profissional frente às tecnologias.

Palavras-chave: Avaliação da informação. Arquivologia. Ciência da Informação. Fenômenos. Paradigmas.

\begin{abstract}
This paper approaches the evaluation of information in Archival Science and Information Science, which is influenced by post-custodial paradigm. It contextualizing appraisal as a archival science practice and the transition to a new paradigm. It is emphasized the emergence of three phenomena, from the awareness of anomalies in theories of evaluation of information / documentation: the first related to analysis of the context of document production, using a post-modern approach; a second phenomenon related to analysis of the information flow and an approach of Information Science inter and transdisciplinary, and finally a third phenomenon related to conceptual analysis of information as proof value, while emancipatory discourse of Archival Science as a disciplinary field and an approach from a Clue-Evidence-Proof Model. Exploratory research with theoretical approach, predominantly qualitative, involving analyzing the national and international literature on the theme. We conclude with the importance of research in the area, emphasizing the lack of literature on the subject with the post-custodial paradigm and propose new questions that can change the status quo established in the evaluation of information in Archival Science, leading to discuss the role of institutions and professional with technology.
\end{abstract}

Keywords: Evaluation of Information. Archival Science. Information Science. Phenomena. Paradigms.

v. 22, n. 50,2017 p. 31-43

ISSN $1518-2924$

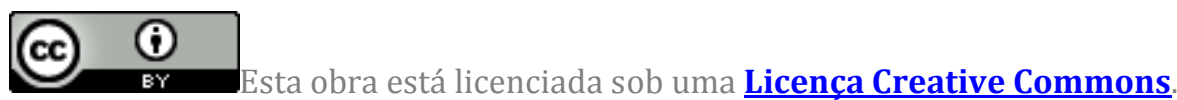




\section{INTRODUÇÃO}

Propomos neste artigo a apresentação de uma investigação que buscou abordagens da avaliação da informação com a aplicação de diferentes métodos e modelos informacionais, avaliação esta iniciada por aquela contida em acervos arquivísticos, mas estendendo-se por toda informação orgânica que é produzida por uma Instituição ou Organização.

Um dos pontos-chave para compreender a problematização, objetivos e interesses da pesquisa é a mudança de paradigma, conceito que nos remete a concepção de Kuhn (1996) de reconstrução de teorias, princípios, métodos e aplicações em determinada área de estudo. Portanto, dentro da Arquivologia e da Ciência da Informação, veremos as diferenças entre o paradigma custodial e o pós-custodial, primeiramente abordado por Ham (1981); Cook (1997); mas também desenvolvido por Silva e Ribeiro (2011); e no que influenciam a abordagem sobre a avaliação da informação.

Para chegarmos a avaliação é imprescindível compreendermos quais são os valores que a fundamentaram historicamente. A avaliação em Arquivologia é impulsionada pela dicotomia entre os valores dos documentos administrativos versus documentos históricos, movimento que teve início com a tecnicização e a manualização arquivística a partir do Manual dos Holandeses (MULLER, FEITH, FRUIN, 1898), foi discutido por Jenkinson (1922) em relação ao caráter único, autêntico e imparcial dos arquivos e culminou no estabelecimento dos valores primários e secundários dos documentos (SCHELLENBERG, 2003).

A avaliação constitui-se em uma das funções fundamentais da Arquivologia, juntamente com as funções de criação, aquisição, conservação, classificação, descrição e difusão (ROUSSEAU, COUTURE, 1998, p. 265). Os métodos de avaliação seguiram os contextos e necessidades históricas, nascendo da demanda na racionalização física dos suportes documentais até perspectivas dos efeitos sociais que estes registros podem produzir. Este trabalho procura enquadrar novas abordagens, derivadas da percepção de anomalias no paradigma tradicional vigente e construídas a partir de um paradigma emergente, que se posiciona inter e transdisciplinarmente no contexto social.

\section{DA REVOLUÇÃo CIENTÍFICA E A TRANSIÇÃO PARA UM NOVO PARADIGMA}

Veremos neste tópico os paradigmas custodial e pós-custodial da informação, essencial para o entendimento das diferenças históricas, teóricas e metodológicas que encontraremos na análise da avaliação em Arquivologia.

Quando Thomas Kuhn traz o conceito de paradigma, ele refere-se "as realizações científicas universalmente re-conhecidas que, durante algum tempo, fornecem problemas e soluções modelares para uma comunidade de praticantes de uma ciência" (KUHN, 1996, p.13). A transição de um paradigma para outro, por sua vez, se dá a partir da percepção de anomalias, ou novos fenômenos que tornam-se incongruentes com o paradigma vigente, a crise na ciência normal, a revolução científica e o estabelecimento de um novo paradigma, com a adequação de uma nova estrutura que comporte as descobertas e inovações decorrentes do fazer científico. 
Em nossa análise é fundamental a compreensão dos conceitos de anomalia e paradigma de Kuhn, pois irá demonstrar como acontece o processo de descoberta e revolução científica, associado aqui aos conceitos e métodos aplicados a avaliação da informação em Arquivologia e Ciência da Informação. A anomalia surge da consciência de problemas que o paradigma vigente não consegue responder de forma satisfatória e pode ser considerada como um contraexemplo de um paradigma. Kuhn demonstra esta relação

A descoberta começa com a consciência da anomalia, isto é, com o reconhecimento de que, de alguma maneira, a natureza violou as expectativas paradigmáticas que governam a ciência normal. Segue-se então uma exploração mais ou menos ampla da área onde ocorreu a anomalia. Esse trabalho somente se encerra quando a teoria do paradigma for ajustada, de tal forma que o anômalo se tenha convertido no esperado. A assimilação de um novo tipo de fato exige mais do que um ajustamento aditivo da teoria. Até que tal ajustamento tenha sido completado - até que o cientista tenha aprendido a ver a natureza de um modo diferente - o novo fato não será considerado completamente científico. (KUHN, 1996, p.78)

Em Arquivologia e Ciência da Informação trazemos os conceitos de paradigma custodial e pós-custodial para explicar a aderência às abordagens teóricas. Conforme o Dicionário Eletrônico de Terminologia em Ciência da Informação (2007), o paradigma custodial configura-se da seguinte forma:

Este paradigma identifica-se com a Modernidade, pois nasce nela, sob a égide do desenvolvimento e da consagração da História, das instituições memorialísticas e custodiadoras geradas pelo EstadoNação e incorporadas mais tarde (depois da II Guerra Mundial) no Estado Cultural, tais como os arquivos, as bibliotecas e os museus e do pendor técnico/tenicista ou procedimental, apurado ao longo do séc. XX, dos profissionais criados por esse tipo de instituições ou serviços. Caracteriza-se por vários traços fortes que não cabe, aqui desenvolver, mas que é possível resumir deste modo: primado da História como fonte legitimadora e matriz modeladora (formadora); necessidade custodial extrema tanto para alimentar o discurso historiográfico e ideológico de preservação/exaltação da identidade cultural/nacional, como para sustentar o mercado dos bens materiais antigos e raros e dos objectos de Arte (antiquários, alfarrabistas, galeristas); e operacionalização do acesso (controlado) e das condições de custódia através de um corpo de normas e de procedimentos (dimensão técnica), muitos empíricos (baseados no senso comum), vários anacrónicos (em face às sucessivas alterações tecnológicas e outras) e alguns científicos (procedentes, sobretudo, na área do restauro e conservação por intermédio da Química, da Física, da Biologia, etc.). (DELTCi, 2007)

Segundo Silva e Ribeiro (2011), o paradigma custodial parte de práticas normativas e empíricas formadas principalmente na modernidade, com o advento da criação de Arquivos e Bibliotecas Nacionais, situando-se entre 1789 e 1945 (SILVA, RIBEIRO, 2011, p.13). Este é baseado no valor da informação enquanto patrimônio, cultura e história, seguindo o modelo francês que instituiu organizações que serviriam de lugar de memória para a Sociedade e os nacionalismos que o sucederam e fizeram uso desta memória em diversos países. 
Como recorda Cook (1997), a era do paradigma pós-custodial foi assim concebida pela primeira vez por F. Gerald Ham em 1981 na revista American Archivist, levando em conta a revolução no processamento da informação e a forma como os usuários são condicionados por este novo ambiente. Ham (1981, p. 207) afirma que "nossa eficácia enquanto arquivistas nesta nova era depende da nossa capacidade de, entre nosso comportamento passado e novas estratégias, lidar com as oportunidades e os problemas criados por esta revolução". O paradigma pós-custodial leva consigo características da pós-modernidade, trazendo um novo ponto de vista sobre os estudos da informação, tendo em conta o uso das tecnologias da informação e comunicação, a cientificidade e as complexas relações em rede das informações produzidas entre indivíduos e organizações.

A transformação que decorre na mudança de paradigma e a definição do paradigma pós-custodial, informacional e científico também pode ser encontrada no DELTCi:

É emergente porque está a surgir no dealbar, em curso, da Era da Informação e nos meandros de uma conjuntura de transição bastante híbrida, complexa e sujeita a um ritmo de inovação tecnológica e científica quase vertiginoso (a Sociedade pósindustrial, da informação, em rede etc.). A Ciência da Informação trans e interdisciplinar, que defendemos, só é possível no seio de um modo de ver, de perspectivar distinto do modelado pelo paradigma anterior, em que a preocupação pela custódia e a "ritualização" do documento é secundarizada pelo estudo científico e pela intervenção teórico-prática na produção, no fluxo, na difusão e no acesso (comunicação) da informação (representações mentais e emocionais que podem estar em diversos suportes e em mutação constante). (DELTCi, 2007)

Há aqui uma inversão de prioridades e de objeto de estudo, uma ênfase no conteúdo ao invés do suporte e a escolha da informação como objeto científico. 0 documento continuará existindo, porém sob um novo ponto de vista e um novo paradigma (o pós-custodial). Silva e Ribeiro (2011) defendem que "perante esta multiplicação de documentos, com idêntico conteúdo, a informação sobressai como a 'substância' a 'destacar' e, a seguir, porquanto continuará sendo reproduzida e posta, sem limites, a 'circular'. E isto é, obviamente, o oposto de custodiar ou guardar, de fechar, de esconder" (SILVA, RIBEIRO, 2011, p. 67). As diferentes fases pela qual os paradigmas da informação passaram podem ser vistos na figura a continuação: 


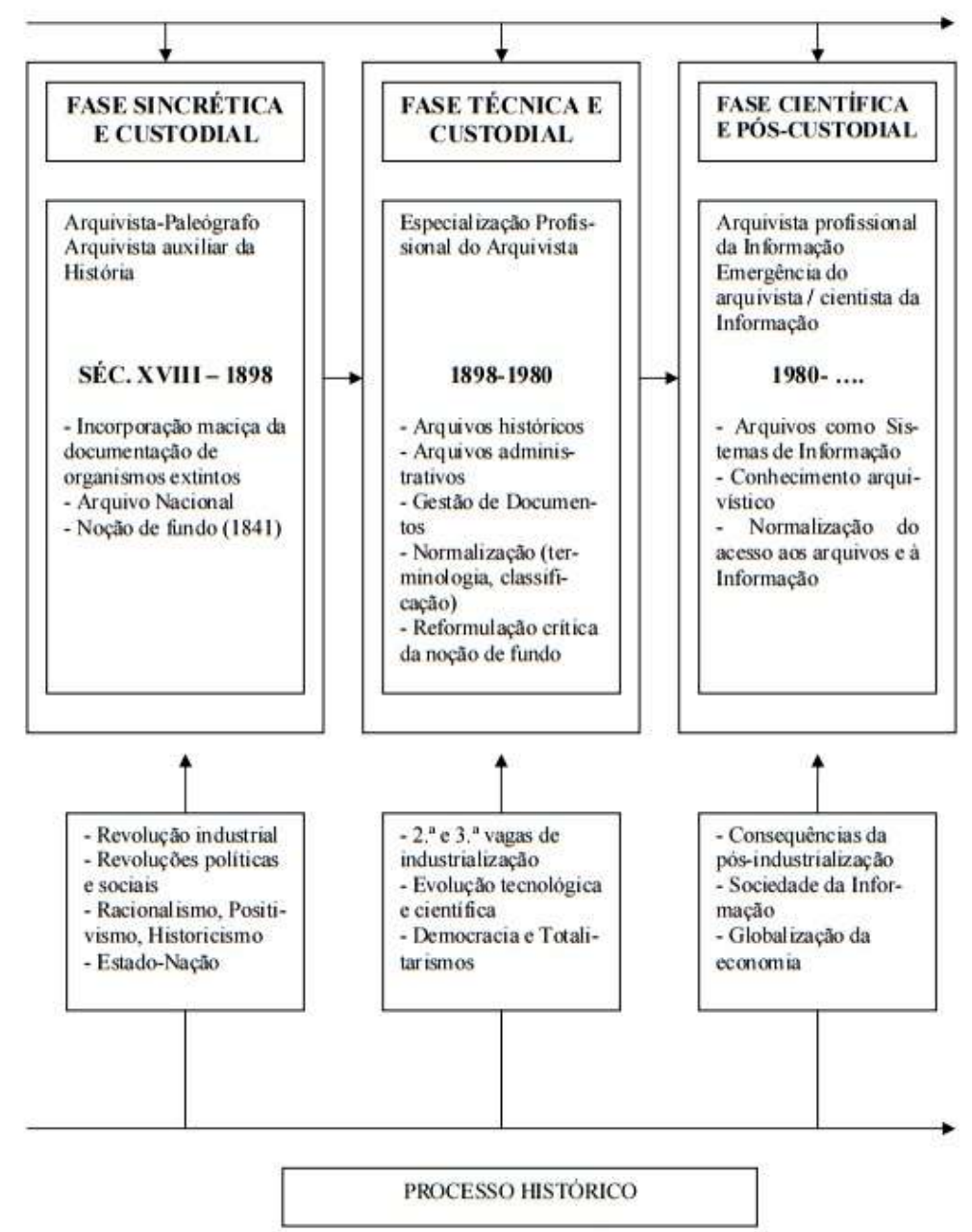

Figura 1: 0 processo informacional relativo aos arquivos.

Fonte: Ribeiro (2011, p. 63).

A sistematização da análise teórica realizada segue a perspectiva de Kuhn sobre a ciência, traçando, portanto, as anomalias que desencadearam questionamentos acerca da normalidade posta dentro de uma disciplina, gerando uma crise sobre o corpo teórico e incitando uma transição paradigmática. A detecção de uma anomalia pode trazer novas perspectivas sobre determinado assunto, no caso abordado aqui, a avaliação em Arquivologia e Ciência da Informação, desde a forma como são vistos os valores aplicados ao documento/informação, até os métodos empregados no processo avaliativo.

Os três fenômenos que serão estudados decorrem de anomalias identificadas sobre a avaliação focalizada somente no documento e não no contexto de produção; na mudança do objeto a ser avaliado, do documento para o fluxo da informação e na concepção e forma como o valor probatório é tratado; referindo-se respectivamente a análise do contexto a partir de uma abordagem pós-moderna de Cook (1997, 1999, 2005); a análise do fluxo informacional e uma abordagem da Ciência da Informação inter e transdisciplinar de Silva e Ribeiro (2000, 2004), e; a análise conceitual da informação como valor de prova e uma abordagem a partir de um Modelo Indício-Evidência-Prova de Rockembach $(2012,2013,2015)$. 


\section{PRIMEIRO FENÔMENO: A ANÁLISE DO CONTEXTO E UMA ABORDAGEM PÓS MODERNA SOBRE AVALIAÇÃO}

Terry Cook (1997) expõe algumas questões sobre as relações entre arquivo e memória, afirmando que a memória social ou coletiva não foi formada ao acaso e que num ambiente pós-moderno é preciso estudar com muito cuidado os processos que determinaram o que valia a pena guardar/lembrar ou eliminar/esquecer, de forma deliberada ou acidentalmente.

Ao rejeitar a teoria de avaliação vigente, defendida por Schellenberg (2003), Cook amplifica a perspectiva e o potencial da avaliação e aprofunda seus objetivos, trazendo uma nova teoria à tona - a Macroavaliação - que ganha espaço, inicialmente no Canadá, e contrapõe tudo que até então era considerado como solução para a redução máxima da documentação produzida e acumulada pelos órgãos governamentais e, ao mesmo tempo, a preservação integral da memória institucional e social.

A Macroavaliação propõe, então, uma avaliação do tipo top-down, a análise estrutural-funcional passa a ser o primeiro passo para a implantação dessa avaliação. É importante salientar, desde já, que a avaliação documental não é suprimida deste processo, mas ocupa um lugar secundário. E a interação dos cidadãos com o órgão governamental ocupa uma posição de destaque, estando no mesmo nível da análise funcional.

A Macroavaliação defende que o processo de avaliação deve ser executado pelo arquivista, mas que o mesmo não deve ter o poder decisório absoluto, desconsiderando toda uma estrutura funcional complexa, bem como a interação da sociedade com estas funções.

A teoria e a metodologia da Macroavaliação implantada na Biblioteca e Arquivos do Canadá pressupõem que os valores da sociedade devem fornecer o contexto para a tomada de decisão em relação à avaliação. E assim, segundo Cook (2005), o papel do arquivista consiste em desenvolver estratégias de avaliação e metodologias que são mais suscetíveis de fornecer uma memória documental abrangente do que aconteceu na sociedade ao longo do tempo. Assim:

Na Biblioteca e Arquivos do Canadá, o principal objetivo é
oferecer aos canadenses provas documentais suficientes de como
o governo tem formulado políticas, tomado decisões,
transacionado seus negócios e interagido com os cidadãos,
deixando pesquisadores e outros usuários às tarefas de analisar e
interpretar o significado dos eventos refletidos através de
documentos de arquivo. (LIBRARY AND ARCHIVES CANADA,
2014, tradução nossa) ${ }^{1}$

A relação social com a estrutura orgânica do Governo - não apenas retratado no Canadá, mas na maior parte dos países - inicia-se na composição dos próprios governantes, na estruturação física e orgânica de seus Ministérios, Secretarias, Departamentos entre outras estruturas que atuam direta ou indiretamente com os Poderes Legislativo, Executivo e Judiciário.

1 At Library and Archives Canada, the primary goal is to offer Canadians sufficient documentary evidence of how government has formulated policy, made decisions, transacted its business and interacted with citizens, leaving researchers and other users the tasks of analyzing and interpreting the meaning of events reflected through archival records. 
Esta relação inicia-se como reflexo da busca constante em suprir e/ou sanar as necessidades da população, logo, esta passa a ser a base defendida na Macroavaliação, pois demonstra a influência direta do cidadão na própria construção estrutural e funcional das instituições públicas. Como bem descrito pela Biblioteca e Arquivos do Canadá (2014), torna-se vital esta análise dos registros acerca do governo, enquanto administrador público e o impacto de suas políticas, programas e serviços sobre os cidadãos dentro do amplo contexto da governança. Assim, "[...] sociólogos postularam que todas as sociedades em diferentes graus reflitam uma interação de três vias das estruturas sociais, funções sociais e cidadãos [...]" (COOK, 2005, p.127, tradução nossa $)^{2}$.

Em relação a esta premissa, Cook (2005) afirma que o arquivista deve dedicar especial atenção aos pontos onde os cidadãos fazem objeções ou sugerem variações aos processos governamentais. São nesses pontos que a melhor documentação sobre o comportamento da sociedade será obtida. 0 resultado dessa documentação, se escolhida como definidora do valor arquivístico dos documentos, refletirá diretamente no conteúdo do arquivo, que oferecerá uma imagem da sociedade: um conjunto das esperanças, atividades e frustrações do público, baseado diretamente naqueles pontos onde a interação do cidadão com o estado é mais vigorosa.

Para obter bons resultados a partir da Macroavaliação, segundo Cook (2005), a pesquisa funcional-estrutural deve ser diferenciada e completa, resultando a identificação dos registros que melhor refletirão os "valores $d a$ sociedade". Isto porque, conforme Cook (2005) a metodologia foca nos processos a partir das formas da sociedade, as quais estão em constante transformação.

\section{SEGUNDO FENÔMENO: A ANÁLISE DO FLUXO DA INFORMAÇÃO E UMA ABORDAGEM INFORMACIONAL E CIENTÍFICA NA AVALIAÇÃO}

A avaliação aqui é tida como uma operação metodológica, que, dentro do Método Quadripolar (BRUYNE et. al, 1977), encontra-se no polo técnico.

Segundo Silva e Ribeiro (2000, 2004), há uma dispersão de critérios e parâmetros na avaliação de informações, fato complicador no estabelecimento de metodologias, e a avaliação pode acontecer sob três vertentes: sobre o desempenho dos serviços de informação (Administração e Gestão); sobre a eficácia e eficiência da recuperação da informação; ou ainda sobre o fluxo da informação, vertente esta que resulta na composição de uma metodologia específica proposta pelos autores.

Para isto, é preciso a compreensão deste objeto de trabalho e de estudo, a informação, que por ser amplamente utilizada por diversas disciplinas em diferentes contextos, possuindo também um grande número de definições distintas, precisa ser melhor delimitada. Este objeto, segundo Silva e Ribeiro, pode ser definido como um "conjunto estruturado de representações mentais codificadas (símbolos significantes) socialmente contextualizadas e passíveis de serem registradas num qualquer suporte material (papel, filme, banda magnética, disco compacto, etc.) e, portanto,

2 "[...] sociologists have posited that all societies to varying degrees reflect a three-way interplay of social structures, social functions, and citizens [...]". 
comunicadas de forma assíncrona e multi-direcionada" (SILVA, RIBEIRO, 2011). Assim sendo, é necessário o entendimento do Arquivo ou Centro de Documentação enquanto Sistema de Informação, trazendo todo background da Teoria Geral dos Sistemas (BERTALANFFY, 1977) aplicável a este objeto de estudo e o estabelecimento das relações sistêmicas entre os elementos que compõem um sistema ou entre subsistemas.

Como critérios e parâmetros, são estabelecidos a pertinência, no sentido de pertencimento a ação de alguém ou a alguma entidade; a densidade, relacionado ao conteúdo informacional primário ou secundário (original ou resumo/síntese, com ou sem cópia); e ainda a frequência, medindo o acesso a informação por parte dos usuários.

As análises da frequência de uso, em especial, podem por em causa o uso intermediário da informação, colocada pela Teoria das Três Idades (Corrente, Intermediária e Permanente) e substituí-la pelo uso de um Sistema de Informação Ativa e Permanente (SI-AP), modelo também proposto pelos autores. Estes três critérios aplicáveis ao fluxo da informação - pertinência, densidade e frequência - são quantificáveis e expostos no quadro abaixo:

Quadro 1: Avaliação sobre o fluxo informacional.

\begin{tabular}{|c|c|c|c|}
\hline & Pertinência & Densidade & Frequência \\
\hline Descrição & $\begin{array}{l}\text { Soma dos objetivos } \\
\text { essenciais + estrutura } \\
\text { orgânica e competên- } \\
\text { cias/funçôes + me- } \\
\text { mória }\end{array}$ & $\begin{array}{l}\text { Eliminar a dupli- } \\
\text { cidade desneces- } \\
\text { sária de informa- } \\
\text { ção, seja na cons- } \\
\text { tatação de cópias } \\
\text { exatas ou replica- } \\
\text { ção da informa- } \\
\text { ção em formatos } \\
\text { diferentes. }\end{array}$ & $\begin{array}{l}\text { Quantificação da } \\
\text { periodicidade de } \\
\text { uso/acesso à in- } \\
\text { formação }\end{array}$ \\
\hline Parâmetros & $\begin{array}{l}\text { Dividido em níveis } \\
\text { A,B,C: } \\
\text { Nivel A: objetivos } \\
\text { essenciais da organi- } \\
\text { zação, constituição } \\
\text { fundacional; } \\
\text { Nível B: funções- } \\
\text { meio; } \\
\text { Nivel C: atos infor- } \\
\text { macionais periféricos. }\end{array}$ & $\begin{array}{l}\text { Ato informacio- } \\
\text { nal pri- } \\
\text { mário/original } \\
\text { dispensa o seu } \\
\text { duplicado absolu- } \\
\text { tamente idêntico } \\
\text { Um ato secun- } \\
\text { dário (resumo ou } \\
\text { sintese) será subs- } \\
\text { tituível pelo pri- } \\
\text { mário, com exce- } \\
\text { çós (ex: rela- } \\
\text { tórios anuais) } \\
\text { Verificar a desa- } \\
\text { tualização da in- } \\
\text { formação }\end{array}$ & $\begin{array}{l}\text { Média padrão: } \\
52 \text { pedidos/ano; } \\
\text { Usos fra- } \\
\text { cos/minimos: } \\
\text { inferiores a } \\
20 \\
\text { Outros quesitos a } \\
\text { serem avaliados: } \\
\text { Identificação dos } \\
\text { usuários } \\
\text { Justificação do } \\
\text { pedido } \\
\text { Ocorrência de } \\
\text { um periodo mui- } \\
\text { to concentrado } \\
\text { ou curto de tem- } \\
\text { po }\end{array}$ \\
\hline Ponderação & $\begin{array}{l}\text { 1 (informação de } \\
\text { nivel A ou B) ou } 0 \\
\text { (informação de nivel } \\
\text { C) }\end{array}$ & $\begin{array}{l}\text { 1 (informação } \\
\text { mais densa) ou } 0 \\
\text { (informação me- } \\
\text { nos densa) }\end{array}$ & $\begin{array}{l}1 \\
\text { máximo/médio) } \\
\text { ou } 0 \text { (uso } \\
\text { minimo, menos } \\
\text { de } 1 \text { vez por se- } \\
\text { mana). }\end{array}$ \\
\hline
\end{tabular}

Fonte: elaboração dos autores, baseado em Ribeiro; Silva (2000, 2004); Ribeiro (2005).

Da análise e cruzamento destes parâmetros, resulta-se em uma tabela que determinará a destinação da informação, conforme demonstrado: 
Tabela 1: Decisão sobre o destino final da informação.

\begin{tabular}{|c|c|c|c|}
\hline PERTINENCIA & DENSIDADE & FREQUÉNCIA & DESTINO FINAL \\
\hline Nível A & 1 & 1 ou 0 & Conservação permanente \\
\hline Nivel A & 0 & 1 & Conservação temporária \\
\hline Nível A & 0 & 0 & Eliminação \\
\hline Nivel B & 1 & 1 ou 0 & Conservação permanente \\
\hline Nivel B & 0 & 1 & Conservação temporária \\
\hline Nível B & 0 & 0 & Eliminaçăo \\
\hline Nível C & 1 ou 0 & 1 & Conservação temporária \\
\hline Nivel C & 1 ou 0 & 0 & Eliminação \\
\hline
\end{tabular}

Fonte: Ribeiro; Silva (2000, 2004); Ribeiro (2005).

\section{TERCEIRO FENÔMENO: A ANÁLISE DO CONCEITO DE PROVA E UMA ABORDAGEM SOBRE O PROCESSO DE (RE)CONSTRUÇÃO DA INFORMAÇÃO}

0 valor probatório dos documentos é tido como um dos discursos emancipadores da Arquivologia enquanto disciplina, a par do caráter orgânico dos documentos, o primeiro sendo associado a qualidade de imparcialidade dos documentos de arquivo e o empenho na manutenção da autenticidade documental, ideias discutidas por Jenkinson (1922), e o segundo como um reflexo do registro das atividades desenvolvidas por uma pessoa ou por um organismo público ou privado. Entretanto, como já exposto por Silva (2006), “a prova não é só produzida por quem a chancela (o escrivão), mas sobretudo por quem a usa ou a quem ela se refere ou pode referir (a parte interessada). Provar ou instituir prova não está imune ao efeito modelador da interpretação subjetiva". (SILVA, 2006, p. 167).

A Sociedade contemporânea é composta por Organizações e Instituições regidas pela complexidade de suas estruturas e relações e pelo uso intenso das Tecnologias da Informação e Comunicação. Portanto, baseando-se em um Paradigma Complexo (MORIN, 1990), Tecnológico (CASTELLS, 2005) e Pós-Custodial (SILVA, RIBEIRO, ano), trazemos a proposta de um Modelo Indício-Evidência-Prova como uma forma de compreender a forma como (re)construímos as informações a partir da apreensão da realidade e do uso de inferências e argumentos. Esta proposta complementa os fenômenos anteriormente citados, porém enxergando a avaliação para além da determinação dos prazos de guarda, configurando-se em uma abordagem crítica sobre o valor atribuído a informação.

0 Modelo Indício-Evidência-Prova possui como objeto de estudo e trabalho a informação, no conceito já exposto por Silva e Ribeiro (2011), e utiliza de uma abordagem inter e transdisciplinar na compreensão do fenômeno. Remete também a Teoria dos Sistemas (BERTALANFFY, 1977), caracterizando-se em um modelo aplicável tanto a informação em suporte analógico, quanto ao meio digital. Faz-se necessário a delimitação dos conceitos de indício, evidência e prova, com base na análise de alguns autores e respectivas teorias trazemos de forma sintética a devida análise conceitual.

Os indícios estão relacionados com o processo de reconstrução da memória a partir de sinais, pistas e vestígios. É algo provável, não no sentido 
de prova, mas no sentido de probabilidade, uma informação sobre algo ou alguém que estatisticamente é provável de ser/ter sido real a partir da análise de seus indícios.

A informação como indício remete ao Método Morelli ou Indiciário, proposto por Ginzburg $(1989,1991)$, onde são verificados os detalhes ou sinais para, com isto, realizar inferências. Como exemplificado por Ginzburg, de forma semelhante, o médico analisa os sintomas, pela sintomatologia, não observando diretamente a doença, mas os sinais indicativos desta. Outro exemplo dado refere-se aos aspectos psicológicos impressos nos artefatos de um falsificador de obras de arte, onde é possível identificar as diferenças entre o original e a cópia (WIND apud GINZBURG, 1989).

Para compormos um conceito de evidência e distinção do conceito de prova, recorremos principalmente a Gil (1988, 1996, 1998, 2005), que se refere a "indicadores epistêmicos" para apontar como o sujeito, linguisticamente, mostra os fatos e objetos como mais ou menos evidentes. 0 termo evidência vem do latim evidentia: possibilidade de ver, clareza, de videre, ver (MORFAUX; LEFRANC, 2005, p. 214), também expressa pelo verbo "[...] video: ex video é uma vidência que vem de dentro" (GIL, 1998. p. 84).

Portanto, a evidência é um complexo sistema composto pelos sentidos humanos, cognição e a linguagem. São respectivamente a entrada do sistema, pelo o que foi captado pelos sentidos, a apreensão do que foi observado e a saída do sistema manifestando a evidência. Por isto, a evidência possibilita um grau variável de certeza sobre aquilo que se está observando ou afirmando, em uma relação entre a realidade e o sistema de crenças e julgamentos de um indivíduo. Conforme Rockembach (2012) maiores níveis de evidência podem ser alcançados tendo em consideração uma série de questionamentos sobre:

- a vigilância epistêmica;

- a forma de apresentação da informação;

- a completude das informações;

- o cumprimento dos objetivos de informar;

- a credibilidade da autoria;

- a organização e recuperação da informação.

No surgimento de teorias concorrentes sobre o mesmo fato, procedese um modo de diminuir as divergências. Por sua vez, a prova nasce da necessidade de validação de determinada informação ou conjunto de evidências, e isto não está livre da intencionalidade do sujeito. A prova, portanto, está relacionada a um processo de legitimação da informação, buscando também normatizar o processo, definindo o que pode ser e como pode ser considerado comprobatório. Este processo acontece não só âmbito do Direito, que tem o poder de julgar sobre o mérito, mas inclusive na própria Ciência, pois a prova científica precisa ser validada por testes e por uma comunidade de pesquisadores.

A natureza de cada um destes conceitos - indício, evidência e prova são distintas, porém complementares, e são expressas no quadro abaixo, que exemplifica também as aplicabilidades em ambientes digitais: 
Quadro 2: Características do Modelo Indício-Evidência-Prova.

\begin{tabular}{|c|c|c|}
\hline $\begin{array}{l}\text { Dimensões da } \\
\text { informação }\end{array}$ & $\begin{array}{l}\text { Características e questões } \\
\text { importantes }\end{array}$ & Exemplos em ambientes digitais \\
\hline Indício & $\begin{array}{l}\text { Possui natureza probabilística. } \\
\text { Informação produzida de forma não- } \\
\text { intencional. Preocupação com a } \\
\text { privacidade dos dados dos usuários. }\end{array}$ & $\begin{array}{l}\text { Registro e análise das preferências dos } \\
\text { usuários e dos termos utilizados para } \\
\text { pesquisa, uso de tecnologias para } \\
\text { coleta de dados produzidos de forma } \\
\text { contextual (cookies) }\end{array}$ \\
\hline Evidência & $\begin{array}{l}\text { Possui natureza informativa. Não exige } \\
\text { formalidades, informação orgânica } \\
\text { produzida intencionalmente. }\end{array}$ & $\begin{array}{l}\text { Informação produzida e } \mathrm{e} \\
\text { comunicada/compartilhada em meios } \\
\text { digitais. }\end{array}$ \\
\hline Prova & $\begin{array}{l}\text { Possui natureza normativa. Exige } \\
\text { validação, exercício do Direito Autoral. }\end{array}$ & $\begin{array}{l}\text { Legitimação jurídica das informações } \\
\text { em ambientes digitais. Certificação e } \\
\text { assinatura digital. }\end{array}$ \\
\hline
\end{tabular}

Fonte: Rockembach (2015).

\section{CONSIDERAÇÕES FINAIS}

A exposição de paradigmas é fundamental para demonstrarmos pelo menos três aspectos importantes que justificaram a pesquisa nesta área. 0 primeiro deve-se a abordagem da avaliação sob uma perspectiva diferenciada, sob o paradigma pós-custodial, informacional e científico. 0 segundo aspecto relevante diz respeito à existência de pouca literatura sobre o tema com o viés pós-custodial, tentando com este projeto reunir e produzir referências sobre o assunto. 0 terceiro aspecto refere-se à possibilidade de suscitar novos questionamentos que podem quebrar o status quo estabelecido na avaliação em Arquivologia, levando a discutir o papel das Instituições e do profissional frente às tecnologias, que estão sempre em movimento evolutivo e adaptativo aos interesses e necessidades dos usuários.

Estudar como a informação é gerada compreende também em valorizar o seu contexto orgânico, promovendo uma revisão das abordagens anteriormente aplicadas a avaliação. Se a análise do contexto já era um elemento essencial apontado por Cook (1997, 1999, 2005), aqui, além do contexto de produção da informação, outro fenômeno se destaca, pois o objeto de estudo também se modifica, do documento para a informação, abordagem da avaliação do fluxo informacional proposta por Silva e Ribeiro (2000, 2004).

A abordagem conceitual e teórico-prática do Modelo IndícioEvidência-Prova, proposto por Rockembach (2012, 2013, 2015), propõe também esta reflexão sobre o processo de (re)construção da memória e informação. Ao mudar o objeto de pesquisa da avaliação, do documento para a informação, o objetivo passa a ser a escolha das evidências significativas e suficientes que melhor refletem o impacto das funções e a interação do público com as mesmas.

\section{REFERÊNCIAS}

BERTALANFFY, Ludwig Von. Teoria geral dos sistemas. 3. ed. Petrópolis: Vozes, 1977. 
BRUYNE, Paul de; HERMAN, Jacques e SCHOUTHEETE, Marc de. Dinâmica da pesquisa em ciências sociais: os pólos da prática metodológica. Rio de Janeiro: Francisco Alves, 1977.

CASTELLS, Manuel. A Sociedade em rede. Volume I. 8a edição. Tradução de Roneide Venâncio Majer. São Paulo: Paz e Terra, 2005.

COOK, Terry What is past is prologue: A history of archival ideas since 1898, and the future paradigm shift. Archivaria, 43, spring 1997.

Archival appraisal and collection: issues, challenges, new approaches. NARA 2 Auditorium: College Park, Md., USA. 22 April 1999.

Macroappraisal in theory and practice: origins, characteristics, and implementation in canada, 1950-2000 Archival Science n.5, 2005.p.101-161.

DICIONÁRIO ELETRÔNICO DE TERMINOLOGIA EM CIÊNCIA DA INFORMAÇÃO (DELTCi). Vitória, E.S.: Porto: DCI - CCEJ da UFES, SAJCC da FLUP - CETAC.Media, 2007. Disponível em: < https://paginas.fe.up.pt/ lci/index.php/1668>.Acesso em 28 abr. 2016.

GIL, Fernando. Acentos. Lisboa: Imprensa Nacional Casa da Moeda, 2005.

Modos da evidência. Lisboa: Imprensa Nacional Casa da Moeda, 1998.

Provas. Lisboa: Imprensa Nacional Casa da Moeda, 1988.

Tratado da evidência. Lisboa: Imprensa Nacional Casa da Moeda, 1996.

GINZBURG, Carlo. "Chaves do mistério: Morelli, Freud e Sherlock Holmes." ECO, Umberto (Org.) SEBEOK, Thomas 0 Signo de Três. São Paulo: Perspectiva. p. 90- 129, 1991.

GINZBURG, Carlo. Mitos, emblemas, sinais: morfologia e historia. São Paulo: Companhia das Letras, 1989.

HAM, F. Gerald. Archival strategies for the post-custodial era. The American Archivist, v.44, n. 3, 1981.

JENKINSON, Hilary. A manual of archive administration. Oxford:Clarendon Press, 1922.

KUHN, Thomas Samuel. A estrutura das revoluções científicas. 4. ed. São Paulo: Perspectiva, 1996.

LIBRARY AND ARCHIVES CANADA. Appraisal Methodology: Macro-Appraisal and Functional Analysis. Disponível em: <http://www.bac-lac.gc.ca/eng/services/governmentinformation-resources/disposition/records-appraisal-dispositionprogram/Pages/government-records-appraisal-disposition-program.aspx>. Acesso em 18 maio, 2016.

MORIN, Edgar. Introdução ao Pensamento Complexo. Lisboa: Instituto Piaget, 1990.

MORFAUX, Louis-Marie, LEFRANC, Jean. Novo Dicionário da filosofia e das Ciências Humanas. Lisboa: Instituto Piaget, 2005.

MULLER, Samuel. FEITH, Johan. FRUIN, Robert. Manual de arranjo e descrição de arquivos. Tradução de Manoel Adolpho Wanderley. Disponível em:

$<$ http://www.portalan.arquivonacional.gov.br/media/manual_dos_arquivistas.pdf $>$. Acesso em 26 abr. 2016.

RIBEIRO, Fernanda. Novos caminhos da avaliação de informação. (2005). Disponível em: 
$<$ http://www.ccje.ufes.br/arquivologia/deltci/textos/Novos_caminhos_para_avaliacao_infor macao_Fernanda_Ribeiro.pdf>. Acesso em 28 abr. 2016.

A Arquivística como disciplina aplicada no campo da Ciência da Informação.

Perspectivas em Gestão \& Conhecimento, João Pessoa, v. 1, n.1, p. 59-73, jan./jun. 2011.

RIBEIRO, Fernanda; SILVA, Armando Malheiro da. A avaliação em arquivística: reformulação teórico-prática de uma operação metodológica. Lisboa: Páginas A\&B, 2000.

A avaliação de informação: uma operação metodológica. Lisboa: Páginas A\&B, 2004.

ROCKEMBACH, Moisés. Modelo de evidência da informação em plataformas digitais: estudo exploratório no âmbito da ciência da informação. Porto, 2012. Tese (Doutorado em Informação e Comunicação em Plataformas Digitais) - Universidade do Porto / Universidade de Aveiro.

Evidência da Informação em plataformas digitais: da reflexão teórica à construção de um modelo. Informação Arquivística, v. 2, p. 89-109, 2013.

Evidência da Informação no contexto dos arquivos digitais.Pontodeacesso, v.9, n.2, 2015. Disponível em: <www.portalseer.ufba.br/index.php/revistaici/article/view/12258 2015> Acesso em 12 mar. 2016.

ROUSSEAU, Jean-Yves; COUTURE, Carol. Os fundamentos da disciplina arquivística. Lisboa: Publicações Dom Quixote, 1998.

SCHELLENBERG, Theodore Roosevelt. Modern Archives: principles and techniques. Chicago: The Society of American Archivists, 2003. Disponível em:

$<$ http://www.archivists.org/publications/epubs/ModernArchives- Schellenberg.pdf >. Acesso em: 10 abr. 2016.

SILVA, Armando Malheiro da; et al. Arquivística: teoria e prática de uma ciência da informação. Porto: Ed. Afrontamento, 1998. 